\title{
Efecto de la Adición de Lactosuero al Queso Costeño Amasado
}

Diofanor Acevedo*, José D.C. Jaimes, Carmen R. Espitia

Universidad de Cartagena, Facultad de Ingeniería, Departamento de ingeniería de Alimentos, Avenida el Consulado, Calle 30 No. 48-152. Cartagena, Bolívar-Colombia (e-mail: diofanor3000@gmail.com)

* autor a quien debe ser dirigida la correspondencia

Recibido Mar. 31, 2014; Aceptado Jun. 10, 2014; Versión final recibida Jul. 11, 2014

\section{Resumen}

Se evaluó el efecto de la incorporación de lactosuero sobre las características fisicoquímicas y de textura del queso costeño amasado. Se realizaron cuatro formulaciones con tres repeticiones. Todas las formulaciones tuvieron fija la materia grasa (MG) con 3.2\%, y se varió el contenido de lactosuero (LS). Formulación 1: Leche 3.2\% MG (Control); Formulación 2: Leche 3.2\% MG + 2\% LS; Formulación 3: Leche $3.2 \% M G+4 \%$ LS; Formulación 4: leche 3.2\% + 6\% LS. Se realizaron pruebas fisicoquímicas a leche y quesos y análisis de perfil de textura (TPA) a quesos. Los resultados señalan que la incorporación de concentrado de proteínas del lactosuero al queso produce un aumento del rendimiento. La adición de lactosuero afecta las características texturales de los quesos. La dureza de los quesos, y por tanto la masticabilidad disminuyó a medida que se aumentó la incorporación de lactosuero. La adhesividad, cohesividad y elasticidad aumentó con la adición de lactosuero.

Palabras clave: lactosuero, queso costeño amasado, TPA, características texturales

\section{Effect of the Addition of Whey to Kneaded Coastal Cheese}

\begin{abstract}
The effect of whey on the physicochemical characteristics and texture kneading coastal cheese was evaluated. Four formulations with three replicates were performed. All formulations had fixed the fat amount (MG) with $3.2 \%$, and the content of whey (LS) was varied. Formulation 1: $3.2 \%$ Fat Milk (Control); Formulation 2: Milk 3.2\% MG + 2\% LS; Formulation 3: Milk 3.2\% MG + 4\% LS; Formulation 4: milk 3.2\% + $6 \%$ LS. Physicochemical tests were performed for milk and cheese, and texture profile analysis (TPA) for cheese. The results show that the addition of concentrated cheese whey proteins results in increased yield. The addition of whey affects the textural characteristics of the cheese. The hardness of the cheese, and thus the chewiness decreased as the addition of whey increased. Also, adhesiveness, cohesiveness and elasticity increased with the addition of whey.
\end{abstract}

Keywords: whey, coastal cheese kneading, TPA, textural features 


\section{INTRODUCCIÓN}

El queso costeño es autóctono de la Región Caribe Colombiana, es prensado, no madurado, posee un alto contenido de sal, bajo porcentaje de humedad por lo cual su conservación es mayor que la de los otros quesos. Se utiliza en la industria panadera especialmente para la elaboración de buñuelos, producto típico de Colombia. Se clasifica como queso semiduro, con alto contenido en materia grasa. Tradicionalmente su forma es en bloques de sección rectangular su apariencia externa es de color crema, sin brillo y de superficies irregulares. Su apariencia interna presenta una textura abierta, de consistencia dura y seca que no se desbarata fácilmente y con un sabor bastante salado (Calderón et al., 2011; López-Tenorio et al., 2012). Existen dos tipos de queso costeño: amasado y picado. Ambos tienen una apariencia externa de color crema suave, con poca brillantez. El costeño picado tiene algunos ojos, textura dura y seca, y no se deshace fácilmente cuando se frota entre los dedos. Por otro lado el queso costeño amasado es moderadamente duro, suelta poco agua, tiene pocos ojos y se deshace fácilmente cuando se frota ente los dedos (Espinal, 2000).

La leche es la materia prima con la cual se elabora el queso (Conti et al., 2012; Granados et al., 2010). La producción de quesos demanda gran cantidad de leche, para obtener un kilogramo de queso se necesitan aproximadamente 10 litros de leche y se generan 9 litros de lactosuero como subproducto. El suero de leche es el residuo líquido que se obtiene mayoritariamente después de la separación de la cuajada en la elaboración de quesos. En términos generales, el lactosuero contiene más de la mitad de los sólidos presentes en la leche original, incluyendo alrededor del $20 \%$ de las proteínas, la mayor parte de lactosa minerales y vitaminas solubles. De acuerdo a un trabajo de la FAO, el suero, residuo líquido de la fabricación de queso y caseína, es una de las mayores reservas de proteínas alimentarias que quedan todavía fuera de los canales del consumo humano. Resulta paradójico que aunque este posee un alto valor nutricional debido a su composición en aminoácidos y vitaminas, y que sus proteínas constituyen el $20 \%$ del total de las proteínas de la leche este subproducto industrial es poco aprovechado, y además su vertido en las aguas residuales de la industria provoca graves problemas de contaminación ambiental (Acevedo, 2010).

Para la industria alimentaria, el suero constituye una fuente económica de proteínas, que otorga múltiples propiedades de aplicación en una amplia gama de alimentos, debido a sus diversas capacidades funcionales. Los productos de suero mejoran la textura, realzan el sabor y color, presentan características de emulsificantes y estabilizantes, mejoran las propiedades de flujo, entre otras propiedades tecnofuncionales, lo que posibilita incrementar, la calidad de muchos productos alimenticios (Arteaga et al., 2009; Fox, 2001; Candioti et al., 2001). Por tal motivo, progresivamente el suero se ha ido industrializando y utilizando en mayor volumen en la elaboración de productos para alimentación humana, además del tradicional uso en alimentación animal. Así, su uso en bebidas fermentadas, productos de panadería, repostería, dulces, además de ser fuente de productos químicos y farmacéuticos como ácido láctico, alcohol etílico, etc (Arteaga et al., 2009; Balagdatas et al., 2003). Las investigaciones acerca de la adición de lacto suero en la elaboración de queso es limitada. Arteaga et al., (2009) caracterizaron el queso chanco enriquecido con suero lácteo en polvo. Estos autores evaluaron la influencia ejercida por el agregado de proteínas séricas, sobre los cambios bioquímicos ocurridos en la maduración del Chanco. Sus resultados indicaron que la adición de suero al proceso de Queso Chanco es factible pero en niveles limitados. Al agregar la proteína coagulada o en forma de concentrado se obtiene un aumento en el rendimiento, sin embargo puede provocar alteraciones importantes en la composición, textura, cuerpo y contenido de humedad, como en el queso Cheddar (FAO, 1986; Jameson y Lelievre, 1996). La capacidad de retención de agua de las proteínas del lactosuero, sobre todo si han sido sometidas a un proceso de desnaturalización, influye en la obtención de quesos con mayores contenidos de humedad (Angulo, 2005; Jameson y Lelievre, 1996; Lo y Bastian, 1998). Los principales problemas de la adición de proteínas de lacto suero al queso, son debido la resistencia de estas proteínas a la acción de las enzimas proteolíticas normalmente presentes en el queso, como resultado, el sabor neutro de las proteínas séricas puede enmascarar el gusto y aroma característicos de los productos de degradación de la caseína, afectando al sabor del producto final. Por otro lado, las proteínas del lacto suero son inertes a la acción de las enzimas del cuajo, lo que contribuiría a lo declarado anteriormente (Angulo, 2005). El objetivo de este trabajo fue evaluar el efecto de la incorporación de concentrado de proteínas del lactosuero sobre las características fisicoquímicas y textura del queso costeño amasado.

\section{MATERIALES Y MÉTODOS}

\section{Adición de lactosuero}

El concentrado de lactosuero fue reconstituido al $50 \% \mathrm{p} / \mathrm{p}$ en agua a $45^{\circ} \mathrm{C}$ y luego sometido a un tratamiento térmico $\left(70^{\circ} \mathrm{C}\right.$ durante 10 minutos), enfriado y adicionado junto a la leche para obtener una mezcla 
estandarizada. Se realizaron 4 formulaciones el mismo día con 3 repeticiones cada uno. Formulación 1: Leche con 3,2\% de materia grasa (Control); Formulación 2: Leche con 3,2\% materia grasa+2\% de suero; Formulación 3: Leche con 3,2\% materia grasa+4\% de suero; Formulación 4: leche con 3,2\% materia grasa $+6 \%$ de suero.

\section{Elaboración del queso costeño amasado}

La filtración de la leche se realizó con coladores o cedazos en acero inoxidable. Luego se mezcló la leche con el lactosuero reconstituido y se elevó la temperatura a $68^{\circ} \mathrm{C}$. Se adicionaron $15 \mathrm{~g}$ de cloruro de calcio por cien litros leche 15 minutos antes de la adición del cuajo. Se adicionaron $2,5 \mathrm{~g}$ de cuajo por $100 \mathrm{~g}$ de leche a $32^{\circ} \mathrm{C}$ y dejó actuar durante 30 minutos. El corte de la cuajada se realizo para aumentar el área de la superficie y acelerar la expulsión del lactosuero. El momento óptimo de cortar la cuajada se reconoce, realizando un corte y luego levantando con el cuchillo la cuajada, de tal manera que se puedan observar las paredes, éstas deben ser lisas y brillantes, el lactosuero sale amarillento y casi transparente. Después del corte de la cuajada con lira, se dejó en reposo, luego se agitó por 10 minutos suavemente facilitando la sinéresis y el rompimiento del grano. Posteriormente se exprimió dentro del lactosuero, con las manos en el fondo y paredes del recipiente de cuajado. Se adicionó cloruro de sodio al $8 \%$ con relación a la cantidad de queso, luego se moldeó y prensó la cuajada, para que la humedad de la superficie estuviese entre 6 y $7 \%$, para proveer al queso de una corteza que lo proteja del medio ambiente, de ataques de microorganismos, insectos y daños físicos por manipulación y transporte. Finalmente se enfrió de 4 a $6 \stackrel{\circ}{\circ}$, por un periodo de 12 a 18 horas, dependiendo del tamaño del queso.

\section{Pruebas fisicoquímicas}

Se realizaron análisis de $\mathrm{pH}$, acidez titulable, materia grasa, proteína total, sólidos totales, lactosa, cenizas y cloruros de acuerdo a la Norma Técnica Colombiana (NTC) 750 (2000) que se basa en los métodos de la A.O.A.C. (2003). Los análisis se realizaron por triplicado a la leche, lactosuero y queso como producto final.

\section{Análisis del perfil de textura (TPA)}

Las muestras se obtuvieron con un sacabocados de acero inoxidable de $20 \mathrm{~mm}$ de diámetro, de modo de obtener cilindros homogéneos de $17 \mathrm{~mm}$ de altura y las superficies expuestas a ensayos de compresión se lubricaron con aceite de maíz de primera calidad, para disminuir la fricción. Se realizó un TPA con un Analizador de Textura Universal Stable Micro System TAXT2i. Se efectuaron dos compresiones cíclicas bajo las siguientes condiciones operativas: deformación del $20 \%$, velocidad de $0,8 \mathrm{~mm} \mathrm{~s}$ y tiempo de recuperación de 1 segundo. Se realizaron diez réplicas por cada muestra de queso. A partir de la curva fuerza en Newton (N) vs. tiempo en segundos (s) se midieron la dureza ( $N$ ), adhesividad ( $N$ x s), elasticidad, cohesividad, gomosidad(N) y masticabilidad $(\mathrm{N})$.

\section{Análisis de datos}

En la investigación, se manejó un diseño experimental totalmente aleatorio. Las determinaciones se efectuaron por triplicado y los resultados expresados como la media con su desviación estándar. Se utilizó el programa PHARM / PCS versión 4 y se calculó la media y la desviación estándar de los resultados en los análisis efectuados.

\section{RESULTADOS Y DISCUSIÓN}

\section{Composición proximal del concentrado de lactosuero}

La composición proximal del concentrado de proteína de lactosuero se muestra en la Tabla 1. Los contenidos proximales del lactosuero concentrado son parecidos a los reportados por Cori et al., (2006) en su trabajo de obtención y caracterización de dos concentrados proteicos a partir de biomasa de Kluyveromyces marxianus var. Marxianus cultivada en suero lácteo desproteinizado.

Tabla 1: Composición proximal de concentrado de lactosuero

\begin{tabular}{|c|c|}
\hline Componentes & Porcentaje (\%p/p) \\
\hline Ceniza & $4,6+/-0,02$ \\
\hline Grasa & $4,1+/-0,40$ \\
\hline Carbohidratos & $8,6+/-0,56$ \\
\hline Humedad & $6,8+/-0,03$ \\
\hline Proteína & $75,86+/-1,23$ \\
\hline
\end{tabular}




\section{Composición proximal y rendimiento de leche y quesos costeños amasados}

La Tabla 2 muestra los contenidos proximales de la leche empleada como materia prima para la elaboración del queso costeño amasado, en los diversos tratamientos. Esta leche cumple con los requerimientos exigidos por la NTC 399 (2002), y se encuentra dentro de los parámetros esperados.

Por otro lado los resultados de los análisis proximales de los quesos amasados obtenidos concuerdan con los resultados reportados por Arteaga et al., (2009) en su trabajo de caracterización de queso chanco enriquecido con suero lácteo en polvo. Por otro lado de acuerdo a la NTC 750 (2000) que estipula los requisitos mínimos de los quesos en Colombia los quesos costeños amasados elaborados en esta investigación tienen designación según su consistencia y contenido de materia grasa como quesos duros ó firme semiduros y semidescremados.

Tabla 2: Composición proximal y rendimiento de leche y quesos costeños amasados

\begin{tabular}{|c|c|c|c|c|c|}
\hline $\begin{array}{c}\text { Características } \\
\text { fisicoquímicas }\end{array}$ & Leche & T1 & T2 & T3 & T4 \\
\hline Humedad (\%) & $88+/-1,23$ & $51,76+/-1,45$ & $52,0+/-1,32$ & $52,8+/-0,78$ & $53,2+/-0,54$ \\
\hline Materia grasa (\%) & $3,20+/-0,56$ & $20,56+/-1,43$ & $21,68+/-0,89$ & $21,79+/-0,23$ & $22,50+/-1,90$ \\
\hline Proteína (\%) & $3,27+/-0,43$ & $19,15+/-0,98$ & $19,50+/-0,78$ & $19,98+/-0,54$ & $20,78+/-1,32$ \\
\hline Cloruros (\%) & $0,12+/-0,01$ & $2,06+/-0,78$ & $2,95+/-0,45$ & $2,95+/-0,23$ & $2,99+/-0,89$ \\
\hline $\mathrm{pH}(\%)$ & $6,77+/-0,05$ & $5,26+/-0,12$ & $5,30+/-0,65$ & $5,30+/-0,35$ & $5,30+/-0,68$ \\
\hline Acidez (\%) & $0,14+/-0,02$ & $0,60+/-0,01$ & $0,60+/-0,06$ & $0,60+/-0,04$ & $0,60+/-0,03$ \\
\hline Rendimiento (\%) & & $14 \%$ & $16,2 \%$ & 19,98 & 20,56 \\
\hline
\end{tabular}

Los resultados mostrados en la Tabla 2 indican que los tratamientos con mayor incorporación de concentrado de proteínas de lactosuero presentaron las más altas concentraciones de proteína total debido a la importante contribución de este ingrediente sobre ese constituyente. Los rendimientos de los queso costeños aumentan con el incremento del concentrado de proteínas del lactosuero, porque las proteínas del lactosuero retienen agua, lo cual se manifiesta en los aumentos del porcentaje de humedad. En otras variedades de queso también se reportan mejoras importantes del rendimiento. Brown y Ernstrom (1982), en la producción de queso Cheddar, usaron suero concentrado por ultrafiltración y lo trataron térmicamente a $75^{\circ} \mathrm{C}$ durante 30 minutos, obteniendo un aumento en un $4 \%$ de rendimiento. Por otro lado Mead y Roupas (2001) analizaron los efectos de incorporar proteínas séricas desnaturalizadas sobre la composición química de queso para pizzas, observando un aumento en el contenido de humedad. Finalmente Simpfendörfer y Benavente (1989), realizaron un estudio sobre utilización de proteínas del suero en la elaboración artesanal de queso Chanco, concluyendo que éstas influyeron positivamente en el rendimiento, recomendando su incorporación como ingrediente en la elaboración artesanal de esta variedad quesera.

La adición de lactosuero enriquece los sólidos de la leche, incrementando a la vez, el rendimiento y el valor nutricional de los quesos. La adición de proteínas del suero a los quesos aumenta la cantidad de agua ligada dado que se forman complejos entre las proteínas desnaturalizadas del suero y la caseína de la leche, por lo que su disponibilidad como solvente es probablemente menor. Este comportamiento influye críticamente en las reacciones bioquímicas de maduración del queso, lo cual junto con el incremento del contenido de lactosa, podría reducir la calidad del producto al elevar la acidez de éste afectando negativamente su consistencia y textura (Arteaga et al., 2009; Jameson y Lelievre, 1996, Kjaergaard y Stapelfeldt, 1991). En la Tabla 2, se observa que el queso control presenta menor contenido de cloruros (sal), que el resto de los tratamientos, esto es debido a que el lactosuero adicionado contiene minerales de calcio, fósforo, sodio, potasio y magnesio, que constituyen las sales y parte de las cenizas de la leche y del suero (Acevedo, 2010).

\section{Análisis de perfil de textura de quesos costeños amasados}

En la Tabla 3 se muestra el TPA para quesos costeños amasados con diferentes incorporaciones de lactosuero. En esta se evidencian diferencias texturales entre un tipo de queso amasado y otro. La adición de lactosuero afecta el proceso y/o algunas de sus características típicas, como las texturales (Arteaga et al., 2009; Jameson y Lelievre, 1996, Kjaergaard y Stapelfeldt, 1991; Steffl et al., 1999).

Los resultados de la Tabla 3 indican que la dureza para los quesos disminuye a medida que se aumenta la incorporación de lactosuero, ya que el queso control (T1) fue el mas duro $(51,98+/-0,12 \mathrm{~N})$, y el queso con mayor incorporación de lactosuero $(6 \%)$ presenta la menor dureza $(15,47+/-0,67 \mathrm{~N})$. Según Arteaga et al., (2009) respecto a la firmeza, los quesos toman una consistencia semiblanda a medida que se incorpora lactosuero. 
La adhesividad es la medida del trabajo necesario para vencer las fuerzas de atracción entre la superficie del alimento y la superficie de otros materiales, por ejemplo: la fuerza requerida para retirar el material que se adhiere al paladar durante se consumo (Osorio et al., 2005). Según Arteaga et al., (2009) esta obedece principalmente a los tipos de enlaces que se presenten entre las micelas de las caseínas, al nivel de proteólisis y al contenido de grasa del producto, por lo que al parecer algunos de estos últimos aspectos se ven afectados por el agregado de suero, lo cual se evidencia en la Tabla 3 , en donde la adhesividad aumentó con la incorporación de lactosuero. Estos mismos autores en su trabajo de caracterización de queso chanco enriquecido con suero lácteo en polvo, encontraron que con la incorporación de lactosuero se reportó un queso mas "pegajoso" de lo normal. Esto lo podemos relacionar con el aumento de adhesividad, cohesividad y elasticidad en la Tabla 3.

La masticabilidad es el producto multiplicativo de la elasticidad por la cohesión y la dureza. Representa la energía requerida para masticar un alimento hasta que este listo para ser deglutido. Entre más maduro este el queso, más energía se requiere para masticarlo, esto debido a que la dureza y la cohesión aumentan en la misma proporción (Osorio et al., 2005), tal como se evidencia en la Tabla 3.

Tabla 3: Análisis de perfil de textura de quesos costeños amasados

\begin{tabular}{|c|c|c|c|c|}
\hline Parámetro & T1 & T2 & T3 & T4 \\
\hline Dureza (N) & $51,98+/-0,12$ & $34,98+/-0,87$ & $29,45+/-0,94$ & $15,47+/-0,67$ \\
\hline Adhesividad (N) & $-0,045+/-0,00$ & $-0,054+/-0,00$ & $-0,038+/-0,00$ & $-0,002+/-0,00$ \\
\hline Cohesividad & $0,37+/-0,00$ & $0,44+/-0,00$ & $0,45+/-0,00$ & $0,54+/-0,00$ \\
\hline Elasticidad & $0,50+/-0,00$ & $0,47+/-0,03$ & $0,50+/-0,00$ & $0,52+/-0,00$ \\
\hline Gomosidad $(\mathrm{N})$ & $27,34+/-1,26$ & $26,98+/-0,65$ & $6,89+/-0,03$ & $7,60+/-0,34$ \\
\hline Masticabilidad & $13,87+/-0,92$ & $12,86+/-0,76$ & $5,23+/-0,45$ & $4,0+/-0,05$ \\
\hline
\end{tabular}

\section{CONCLUSIONES}

Los resultados obtenidos en este estudio señalan que la incorporación de concentrado de proteínas del lactosuero al queso produce un aumento del rendimiento. La adición de lactosuero afecta características texturales de los quesos. La dureza para los quesos disminuyó a medida que se aumentó la incorporación de lactosuero, y aumentó la adhesividad, cohesividad y elasticidad con la adición de este. Entre más maduro este el queso, más energía se requiere para masticarlo, esto debido a que la dureza y la cohesión aumentan en la misma proporción. En general este estudio aborda un tema de amplio para la industria quesera, dado que supone el aprovechamiento de una fuente interesante de proteínas como es el lactosuero, cuya eliminación actual desmedida causa serios problemas ambientales y para el quesero.

\section{REFERENCIAS}

Acevedo, D., Gelificación fría de proteínas de lactosuero, Reciteia, 10(2), 5-23 (2010).

Angulo, C.F., Factibilidad de producción y estudio de rendimiento de queso chanco con incorporación de suero en polvo, Tesis de Maestría, Facultad de Ciencias Agrarias, Universidad Austral de Chile, Valdivia, Chile (2005).

Arteaga, M. y otros tres autores, Caracterización de queso chanco enriquecido con suero lácteo en polvo, Revista Chilena de Nutrición, 36(1), 53-62 (2009).

A.O.A.C.; Association of Official Analytical Chemists, Official Methods of Analysis of AOAC International, 17th edition, Maryland, USA (2003).

Balagdatas, J.V. y otros tres autores, Anticipating market effects of new uses for whey and evaluating returns to research and development, Journal of Dairy Science, 86, 1662-1672 (2003).

Brown, R. y A. Ernstrom, Incorporation of ultrafiltration concentrated whey solids into cheddar cheese for increased yield, Journal of Dairy Science: 65(12), 2391-2395 (1982).

Calderón, A. y otros cinco autores, Efecto de la mastitis subclínica sobre el rendimiento en la fabricación del queso costeño, Biosalud, 10(2), 16-27 (2011). 
Candioti, M.C. y otros tres autores, Susceptibility of whey proteins to the action of commercial proteases used in food processing, Australian Journal of Dairy Technology, 56(1), 35-37 (2001).

Conti, J.P. y otros tres autores, Perfil proteico y peptídico de una base fluida para bebidas funcionales obtenida por fermentación de lactosuero, Información Tecnológica, 23(2), 61-70 (2012).

Cori, M.E. y otros cinco autores, Obtención y caracterización de dos concentrados proteicos a partir de biomasa de Kluyveromyces marxianus var. marxianus cultivada en suero lácteo desproteinizado, Revista Científica, 16(3), 315-324 (2006).

Espinal, G. y S. Barrera, Inventario y desarrollo de la tecnología de productos lácteos campesinos en Colombia, ICTA, Bogotá, Colombia (2000).

FAO (Food and Agriculture Organization of the United Nations), Elaboración de quesos. Manual correspondiente modulo III-B (1986), http://biblioteca.frvm.utn.edu.ar/opac_css/index.php?|vl=serie_see\&id=1. Acceso: 15 Octubre (2013).

Fox, P.F., Milk proteins as food ingredients, International Journal of Dairy Technology, 54(2), 41-55 (2001).

Granados, C., G. Gonzalo y D. Acevedo, Tecnificación, caracterización fisicoquímica y microbiológica del queso de capa de Mompox (Colombia). Rev. Bio. Agro: 8(2), 440-450 (2010).

Jameson, G.W. y J. Lelievre, Effects of whey proteins on cheese characteristics, Bulletin IDF, 313, 3-8 (1996).

Kjaergaard, J. y H. Stapelfeldt, Incorporation of whey proteins in cheese. Including the use of ultrafiltration, Factors affecting the yield of cheese, IDF especial issue, 9301, 88-108 (1991).

López-Tenorio, J.A. y otros tres autores, Evaluación de características físicas y texturales de pandebono, Acta Agronómica, 61(3), 273-281 (2012).

Mead, D. y P. Roupas, Effect of incorporation of denatured whey proteins on chemical composition and functionality of pizza cheese, Journal of Dairy Technology, 56(1), 19-23 (2001).

NTC 399, Instituto Colombiano de Normas Técnicas y Certificación (Colombia), Productos lácteos. Leche Cruda. Cuarta Actualización, Bogotá, Colombia (2002).

NTC 750, Instituto Colombiano de Normas Técnicas y Certificación (Colombia), Productos lácteos. Quesos. Tercera Actualización, Bogotá, Colombia (2000).

Osorio, J.F., H.J. Ciro, y L.G. Mejía, Caracterización reológica y textural del queso EDAM, DYNA, 72(147), 33-45 (2005).

Simpfendöfer, S. y J. Benavente, Utilización de la proteínas solubles del suero en la elaboración artesanal del queso Chanco, Alimentos, 14(3), 23-29 (1989).

Steffl, A. y otros tres autores, Influence of whey protein particles on the renneting properties of milk, Milchwissenschaft, 54(9), 510-513 (1999). 